\title{
Extradural anesthesia with lidocaine combined with fentanyl or methadone to ovariohisterectomy in $\operatorname{dogs}{ }^{1}$
}

\author{
Miriely Steim Diniz ${ }^{I}$, Gláucia Prada Kanashiro"I, Camila Angela Bernardi", Gabriel Montoro Nicácio"II, Renata Navarro Cassu ${ }^{\text {IV }}$ \\ IVMD, Resident, Department of Veterinary Surgery and Anestesiology, Scholl of Veterinary Medicine, Oeste Paulista University (UNOESTE), \\ Presidente Prudente-SP, Brazil. Acquisition of data, helped with technical procedures, collection and processing of study informations, manuscript \\ writing. \\ IIMaster, Full Professor, Department of Veterinary Surgery and Anestesiology, Scholl of Veterinary Medicine, UNOESTE, Presidente Prudente-SP, \\ Brazil. Helped with technical procedures, collection and processing of study informations. \\ IIIFull Professor, Department of Veterinary Surgery and Anestesiology, Scholl of Veterinary Medicine, UNOESTE, Presidente Prudente-SP, Brazil. \\ Helped with technical procedures.

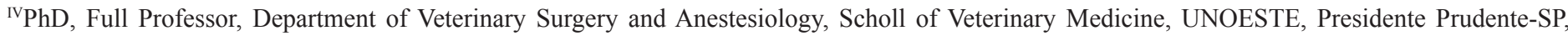 \\ Brazil. Mentor. Responsible for intellectual and scientific content of the study; statistical analysis; critical revision.
}

\section{ABSTRACT}

PURPOSE: To compare the cardiopulmonary effects and the quality of anesthesia of the extradural lidocaine in combination with fentanyl or morphine in bitches undergoing ovariohysterectomy.

METHODS: Sixteen female dogs, were sedated with intramuscular acepromazine $\left(0.05 \mathrm{mg} \mathrm{kg}^{-1}\right)$, followed by anesthetic induction with intravenous propofol $\left(4 \mathrm{mg} \mathrm{kg}^{-1}\right)$, to perform the lumbosacral puncture. The animals were randomly assigned to two treatments: T-F ( $\mathrm{n}=8)$ extradural administration of fentanyl $\left(5 \mu \mathrm{g} \mathrm{kg}^{-1}\right)$, T-M $(\mathrm{n}=8)$ extradural administration of methadone $\left(0.3 \mathrm{mg} \mathrm{kg}^{-1}\right)$. In both treatment groups, opioids were combined with lidocaine, in order to make up a final volume of $0.4 \mathrm{~mL} \mathrm{~kg}^{-1}$. Heart rate (HR), respiratory rate (RR), systolic arterial blood pressure (SABP), intra-operative anesthetic supplementation, blood gases and adverse effects were investigated.

RESULTS: HR, arterial pH and blood gases did not differ between treatments at any time point. RR and SABP decreased after epidural anesthesia, but the values were in terms of the physiological range of dogs. Intra-operative anesthetic supplementation was required in $50 \%$ and $62.5 \%$ of the fentanyl and methadone treated dogs, respectively.

CONCLUSION: The extradural lidocaine in combination with fentanyl or morphine allowed cardiopulmonary stability, however sufficient sensitive blockade was not provided in $100 \%$ of the dogs.

Key words: Anesthesia, Epidural. Analgesics, Opioid. Lidocaine. Fentanyl. Methadone. Dogs. 


\section{Introduction}

One of the most common elective surgical procedures performed in dogs is ovariohysterectomy (OHE). The procedure is normally carried under general anesthesia. Alternatively, extradural anesthesia is an attractive and inexpensive method for retro umbilical surgical procedures. Unlike other anesthetic techniques, extradural anesthesia produces minimal cardiovascular and respiratory depression ${ }^{1}$.

In dogs have been reported maximal spread of anesthetic blockade until to fourth or sixth lumbar vertebra following lumbosacral extradural lidocaine ${ }^{2-4}$ which is usually unsatisfactory to OHE, because the ovarian pedicle is innervated by third and fourth lumbar afferent nerves ${ }^{5}$.

Thus, some studies have proposed the extradural administration of an opioide in combination with lidocaine in an attempt to spread the sensory blockade, optimizing the anesthesia to lower abdominal surgical procedures in $\operatorname{dog} s^{6-9}$.

Morphine administered extradurally in combination with lidocaine provided safe and satisfactory anesthesia for performing OHE in $100 \%$ of the dogs, so that general supplemental anesthesia was not required ${ }^{9}$. Similar results were showed with extradural butorphanol plus lidocaine for dogs undergoing $\mathrm{OHE}^{7}$. In both studies, minimal adverse effects such as nausea, vomiting, and cardiopulmonary depression were reported.

However, despite these favorable results, there are relatively few studies about extradural anesthesia as a single technique for surgical procedures in dogs. The majority of the studies have focused on the effects of the extradural in combination with general anesthesia ${ }^{10-14}$.

The objective of the present investigation was to compare the cardiopulmonary effects and the quality of extradural anesthesia with lidocaine in combination with fentanyl or methadone in bitches undergoing OHE.

\section{Methods}

This study was approved by the Institutional Animal Research Ethical Committee (protocol number 358), and permission for the participation of each dog was obtained from the owner. Sixteen healthy adult, crossbreed, female dogs, which weighed 4.5 to $15 \mathrm{~kg}$ were evaluated. Animals undergoing elective OHE were selected for this study using a physical examination and laboratory tests (complete blood cell count, urea, creatinine, alanine aminotransferase and aspartate aminotransferase).

After withdrawal of food and water for 12 and three hours, respectively, all dogs were sedated with $0.05 \mathrm{mg} \mathrm{kg}^{-1}$ of acepromazine maleate (Acepran 0.2\%, Univet, Sao Paulo, Brazil) administered intramuscular (IM). Twenty minutes after sedation, anesthesia was induced with 4 to $5 \mathrm{mg} \mathrm{kg}^{-1}$ intravenously (IV) propofol (Propovan, Cristalia, Itapira, Brazil), to perform the lumbosacral puncture.

All dogs were prepared for extradural (ED) injection analgesia: hair in the lumbosacral area was clipped, and the dogs were placed in sternal recumbency. Each was randomly assigned to receive $5 \mu \mathrm{g} \mathrm{kg}^{-1}$ of fentanyl (Fentanest, Cristalia, Itapira, Brazil) (T-F, $\mathrm{n}=8$ ) or $0.3 \mathrm{mg} \mathrm{kg}^{-1}$ of methadone (Metadon, Cristalia, Itapira, Brazil) (T-M, $\mathrm{n}=8)$ by the extradural route. In both treatments, the drugs were given in combination with lidocaine (Xilestesin $2 \%$ com vasoconstritor, Cristalia, Itapira, Brazil) to produce a total volume of $0.4 \mathrm{~mL} \mathrm{~kg}^{-1}$. ED injection was performed at the lumbosacral (L7-S1) space. Correct spinal needle placement was confirmed by a lack of resistance to injection ${ }^{3}$. The drugs were injected over a two minutes period.

Following the ED injection, the animals were maintained in sternal recumbency for 20 minutes, for the uniform distribution of the drugs in the epidural space and due to the latency period of the opioids and lidocaine. After this period, the anesthetic blockade was confirmed by absence of flexor-pinch reflex of pelvic limbs, once the dogs were already aware due to the short central depression induced by propofol. Thereafter, the animals were positioned in dorsal recumbency on a surgical bed for the OHE. All animals underwent routine OHE through a 2 -to $3-\mathrm{cm}$ midline incision by the same experienced surgeon.

Ringer's lactate solution $\left(10 \mathrm{~mL} \mathrm{~kg}^{-1} \mathrm{~h}^{-1}\right)$ was infused IV using a peristaltic infusion pump (ST1000, Samtronic, Sao Paulo, Brazil) throughout the surgical procedure.

During the anesthetic procedure, oxygen saturation of hemoglobin $\left(\mathrm{SpO}_{2} \%\right)$ and heart rate $(\mathrm{HR})$ were continuously measured with pulse oximeter (VAMOS plus, Dräger, Sao Paulo, Brazil), with the sensor on the vulva. Systolic arterial blood pressure (SABP) was measured by noninvasive method using a Doppler ultrasonic (Doppler 841-A, Parks Medical Electronics, Las Vegas, EUA), with the width cuff about $40 \%$ of the circumference of the antebrachium. Respiratory rate (RR) was measured by observation of the thoracic movements for one minute. Measurements were made before premedication (Baseline), 15 minutes after premedication administration, five minutes and every ten minutes after the start of surgery.

Arterial blood samples were collected into heparinized syringes from the femoral artery, by puncture. All arterial blood gas samples were stored on ice and analyzed immediately on 
as automated blood gas analyzer (Cobasp, modelo 121, RocheMacromed, Sao Paulo, Brazil). Samples were corrected for body temperature. Arterial blood $\mathrm{pH}$, carbon dioxide partial pressure $\left(\mathrm{PaCO}_{2}\right)$, oxygen partial pressure $\left(\mathrm{PaO}_{2}\right)$, arterial hemoglobin saturation $\left(\mathrm{SaO}_{2}\right)$, arterial bicarbonate concentration $\left(\mathrm{HCO}_{3}{ }^{-1}\right)$ were determined before the pre-anesthetic medication was administered (Basaline), at the time of the ovarian pedicle clamping (IO), and at the end of the surgery (After OHE).

Supplemental anesthesia was provided with a propofol $\left(5 \mathrm{mg} \mathrm{kg}^{-1}\right)$ bolus if extradural anesthesia was unsatisfactory. Any dog showing signs of discomfort, based on an increase in heart rate and/or arterial blood pressure $>20 \%$ of the baseline values ${ }^{18}$, as well as sudden voluntary movements of the forelimbs or head. The total number of propofol doses and their intervals were recorded.

Duration of surgery and the post-anesthetic recovery were recorded as well as the occurrence of adverse effects such as nausea, vomiting and excitement.

Data were recorded as mean $\pm \mathrm{SD}$. The data analyzed using an analysis of variance with the F test followed by Tukey's test using Graphpad software. Differences between treatments at each time point, differences in time for each treatment, and the interaction between treatment and time were investigated. A $\mathrm{P}$-value less than 0.05 was considered significant.

\section{Results}

There were no differences $(\mathrm{p}>0.05)$ between the groups in terms of body weight ( $9 \pm 5$ and $9.2 \pm 2.5 \mathrm{~kg}$ for the T-F and T-M groups, respectively) and surgical time (21 \pm 3 and $22 \pm 2$ minutes for the T-F and T-M groups, respectively).

Heart rate, arterial $\mathrm{pH}, \mathrm{PaCO}_{2}, \mathrm{PaO}_{2}, \mathrm{SaO}_{2}$ and $\mathrm{HCO}_{3}^{-}$did not differ between treatments at any time point (Tables 1 and 2).

Systolic arterial blood pressure did not change between treatment groups, except at five minutes after the start of the surgery, when this parameter was lower in T-F in comparison with T-M (Table 1).

Respiratory rate was not significantly different between treatment groups at any time after extradural administration. However, lower RR was observed at five, ten and 20 minutes after the start of OHE when compared with the baseline values in both groups (Table 1).

There was no significant difference in requirement for supplemental intra-operative anesthesia between treatment groups. Four of the eight dogs $(50 \%)$ in the fentanyl group required propofol during the ovarian manipulation, compared with five $(62.5 \%)$ in the methadone group.

Undesirable side effects were not observed in any of the dogs.

TABLE 1 - Heart rate (HR), respiratory rate (RR), systolic arterial blood pressure (SABP) in dogs treated with lidocaine in combination with fentanyl (T-F, $\mathrm{n}=8)$ or methadone (T-M).

\begin{tabular}{|c|c|c|c|c|c|}
\hline \multirow[b]{2}{*}{ Variable } & \multicolumn{5}{|c|}{ Time (min) } \\
\hline & Baseline & 15 & $5^{\mathrm{s}}$ & $10^{\mathrm{s}}$ & $20^{\mathrm{s}}$ \\
\hline \multicolumn{6}{|c|}{ HR (beats min $^{-1}$ ) } \\
\hline $\mathrm{T}-\mathrm{F}$ & $115 \pm 30$ & $104 \pm 15$ & $119 \pm 25$ & $92 \pm 17$ & $98 \pm 15$ \\
\hline T-M & $123 \pm 33$ & $110 \pm 20$ & $107 \pm 30$ & $98 \pm 23$ & $95 \pm 20$ \\
\hline \multicolumn{6}{|c|}{ RR (breats min $^{-1}$ ) } \\
\hline $\mathrm{T}-\mathrm{F}$ & $40 \pm 24$ & $28 \pm 10$ & $19 \pm 6^{*}$ & $17 \pm 6^{*}$ & $16 \pm 5^{*}$ \\
\hline T-M & $31 \pm 8$ & $24 \pm 9$ & $20 \pm 5^{*}$ & $18 \pm 3^{*}$ & $18 \pm 4 *$ \\
\hline \multicolumn{6}{|c|}{$\mathrm{SABP}(\mathrm{mmHg})$} \\
\hline $\mathrm{T}-\mathrm{F}$ & $131 \pm 19$ & $118 \pm 14$ & $102 \pm 3^{*}$ & $113 \pm 19$ & $110 \pm 16$ \\
\hline $\mathrm{T}-\mathrm{M}$ & $141 \pm 18$ & $120 \pm 12$ & $114 \pm 5^{* \#}$ & $114 \pm 12 *$ & $108 \pm 15^{*}$ \\
\hline
\end{tabular}

Values are shown as mean \pm SD. *Significantly different from baseline values $(\mathrm{p}<0.05)$. ${ }^{*}$ Significantly different from T-F treatment $(\mathrm{p}<0.05)$.

Times listed are baseline, 15 minutes following premedication (15), and 5, 10, 20 minutes following the start of surgery $\left(5^{\mathrm{s}}, 10^{\mathrm{s}}, 20^{\mathrm{s}}\right)$. 
TABLE 2 - Arterial blood gases, $\mathrm{pH}$ and bicarbonate in dogs treated with lidocaine in combination with fentanyl (T-F, n=8) or methadone (T-M).

\begin{tabular}{|c|c|c|c|}
\hline Variables & Baseline & IO & After OHE \\
\hline \multicolumn{4}{|l|}{$\mathrm{pH}$} \\
\hline T-F & $7.38 \pm 0.03$ & $7.38 \pm 0.03$ & $7.36 \pm 0.02$ \\
\hline T-M & $7.38 \pm 0.05$ & $7.35 \pm 0.04$ & $7.34 \pm 0.03$ \\
\hline \multicolumn{4}{|c|}{$\mathrm{PaO}_{2}(\mathrm{mmHg})$} \\
\hline $\mathrm{T}-\mathrm{F}$ & $34 \pm 2$ & $38 \pm 2$ & $36 \pm 5$ \\
\hline T-M & $36 \pm 3$ & $35 \pm 4$ & $37 \pm 5$ \\
\hline \multicolumn{4}{|c|}{$\mathrm{PaO}_{2}(\mathrm{mmHg})$} \\
\hline T-F & $96 \pm 6$ & $96 \pm 6$ & $97 \pm 6$ \\
\hline T-M & $100 \pm 5$ & $98 \pm 6$ & $102 \pm 4$ \\
\hline \multicolumn{4}{|l|}{$\mathrm{Sat}_{\mathrm{O} 2}(\%)$} \\
\hline $\mathrm{T}-\mathrm{F}$ & 98 & 96 & 97 \\
\hline T-M & 97 & 96 & 97 \\
\hline \multicolumn{4}{|c|}{$\mathrm{HCO}_{3}(\mathrm{mmol} / \mathrm{L})$} \\
\hline T-F & $18 \pm 2$ & $21 \pm 3$ & $21 \pm 3$ \\
\hline T-M & $19 \pm 3$ & $20 \pm 3$ & $22 \pm 2$ \\
\hline
\end{tabular}

Values are shown as mean \pm SD.

Times listed are baseline, IO: intra-operative period (at the time of the ovarian pedicle clamping) and after OHE: immediately after the end of the surgery. $\mathrm{PaCO}_{2}$ : carbon dioxide partial pressure; $\mathrm{PaO}_{2}$ : oxygen partial pressure; $\mathrm{HCO}_{3}$ : bicarbonate

\section{Discussion}

The current study confirms previous reports in dogs, which have shown minimal cardiovascular changes after lidocaine in combination with different opioids administered by extradural route $^{4,7,8}$.

Opioid-induced cardiovascular depression is dose and administration route dependent ${ }^{15}$. The incidence of adverse effects is lower after extradural administration when compared with parenteral opioids ${ }^{12,13}$. In the current study, mild reduction was observed in systolic blood pressure after extradural injection in the both treatment groups, however hypotension ( $\mathrm{SABP}<90 \mathrm{mmHg}$ ) was not observed. This result supports the findings of Bosmans et $a l .{ }^{14}$ that reported reduction in blood pressure after ED methadone administration in dogs, however clinical values were maintained. Leibetseder et al. ${ }^{13}$ showed moderate hypotension after ED methadone $\left(0,3 \mathrm{mg} \mathrm{kg}^{-1}\right)$ in combination with an isoflurane concentration of $1.0 \%$ in dogs, but median arterial blood pressure increased with surgical stimulation to values within the normal range. Similar results have been reported following ED fentanyl plus local anesthetic, with minimal cardiovascular changes in dogs undergoing elective $\mathrm{OHE}^{6,16,17}$. In addition, the premedication may have contributed to the reduction of blood pressure due to blockade of $\alpha_{1-}$ receptors by acepromazine maleate ${ }^{18}$. Moreover, the cardiovascular effects of propofol are well documented. It transiently depresses arterial pressure and myocardial contractility similar to the thiobarbiturates ${ }^{19}$. Thus, both the administration of a bolus of propofol at the time of epidural needle placement and the additional doses required during the surgery may reduce the blood pressure.

In dogs, respiratory function is not impaired following extradural anesthesia, unless local anesthetic produce motor blockade of the phrenic nerve at cervical vertebra ${ }^{1}$. However, the use of epidural opioids, particularly morphine, has been associated with respiratory depression, mainly in people ${ }^{15}$. The mechanism of respiratory depression after epidural morphine seems to be related to morphine's low lipid solubility. In comparison with hydrophilic drugs, the rapid uptake of extradural lipophilic compounds reduces their capacity to cause late respiratory depression ${ }^{20}$. Leibetseder et $a l .{ }^{13}$ reported pronounced respiratory depression following methadone intravenous administration, while extradural methadone did not affect respiratory pattern in dogs. Similarly, previous publications have shown minimal changes in respiratory rate and blood gases following epidural fentanyl combined with lidocaine in $\operatorname{dog} s^{6,8,16,17}$, which is in agreement with the results of the current study. All dogs had significantly lower respiratory rate following epidural injection, however, bradypnea was not observed. Additionally, arterial $\mathrm{pH}$ and blood gases remained 
within the physiological range, suggesting that both treatments did not impair the ventilatory status.

Lidocaine has a rapid onset of action. Approximately $1 \mathrm{~mL}$ of $2 \%$ lidocaine per $4.5 \mathrm{~kg}$ of body weight will completely anesthetize the pelvic limbs and posterior abdomen within ten to 15 min after administration ${ }^{1,2}$. Similarly, the more lipophilic opioids such as methadone and fentanyl are able to cross the meninges quite rapidly, resulting in a short onset of action ${ }^{15}$. In human beings, the onset time of effect of ED methadone and fentanyl is about ten to 20 minutes ${ }^{20}$. Thus, in the current study, the surgery was started only 20 minutes after ED injection, when the anesthetic blockade was confirmed by absence of flexor-pinch reflex of pelvic limbs. However, despite the absence of the toe reflexes be associated with surgical anesthesia ${ }^{1}$, supplemental propofol was required in $50 \%$ and $62.5 \%$ in fentanyl and methadone treated dogs, respectively. This result suggests that cranial dispersion of the drugs injected into epidural space was insufficient to reach the cranial lumbar dermatomes, impairing the ovarian manipulation. In dogs, the spread of sensitivity blockade to the upper third lumbar vertebra was showed just in $50 \%$ of the dogs following ED methadone plus lidocaine $\mathrm{s}^{4}$. Similarly, in $40 \%$ of the dogs anesthetized with ED fentanyl in combination with lidocaine was necessary supplemental anesthesia during the ovarian clamping ${ }^{8}$.

Both treatments provided satisfactory post-anesthetic recovery. No adverse effects were observed in the current study, which is in agreement with previous results reported in dogs following extradural opioids in combination with local anesthetics ${ }^{4,6-8}$

\section{Conclusion}

The extradural lidocaine in combination with fentanyl or morphine provides cardiopulmonary stability to dogs undergoing ovariohysterectomy. However, sensitivity blockade was not sufficient to ovarian manipulation in $100 \%$ of the dogs.

\section{References}

1. Torske KE, Dyson DH. Epidural analgesia and anesthesia. Vet Clin North Am Small Anim Pract. 2000;30:860-3.

2. Cruz ML, Luna SPL, Clark RM. Epidural anaesthesia using lignocaine, bupivacaine or a mixture of lignocaine and bupivacaine in dogs. J Vet Anaesth. 1997;24:30-3.

3. Gasparini SS, Luna SPL, Cassu RN, Uiechi E, Crocci AJ. Epidural anaesthesia using ropivacaine, lidocaine or the combination of lidocaine and xylazine in dogs. Cardiorespiratory and analgesic effects. Cienc Rural. 2007;37:418-24.

4. Monteiro ER, Dossi RJO, Antunes AP, Campagnol D, Bettini CM, Choma JC. Effects of methadone or neostigmine in combination with lidocaine for epidural anesthesia in dogs. Arq Bras Med Vet Zootec. 2008; 60:1439-46.

5. Bailey CS, Kitchell RL, Haghighi SS, Johnson RD. Spinal nerve root origins of the cutaneous nerves of the canine pelvic limb. Am J Vet Res. 1988;49:115-9.

6. Aminkov BY. Comparison between lidocaine alone and fentanyl with lidocaine for epidural anaesthesia in dogs. Rev Med Vet. 1996;147:819-24.

7. Ishiy HM, Luna SPL, Gonçalves RC. Uso da lidocaína isolada ou associada à quetamina ou ao butorfanol, em anestesia epidural em cadelas submetidas à ovariosalpingohisterectomia. Rev Bras Cienc Vet, 2002;9:134-6.

8. Cassu RN, Melchert A, Silva APG, Reis AM, Meirelles CC. Lidocaína com vasoconstrictor isolada e associada ao fentanil via peridural em cães. Cienc Rural. 2010;40(3):580-6.

9. Tamanho RB, Oleskovicz N, Moraes AN, Flôres FN, Dallabrida AL, Regalin D, Carneiro R, Pacheco AD, Rosa AC. Anestesia epidural cranial com lidocaína e morfina para campanhas de castração em cães. Cienc Rural. 2010;40(1):115-22.

10. Troncy E, Junot S, Keroack S, Sammut V, Pibarot P, Genevois JP, Cuvelliez S. Results of preemptive epidural administration of morphine with or without bupivacaine in dogs and cats undergoing surgery: 265 cases (1997-1999). J Am Vet Med Assoc. 2002;221:66672.

11. Aprea F, Cherubini GB, Palus V, Vettorato E, Corletto F. Effect of extradurally administered morphine on postoperative analgesia in dogs undergoing surgery for thoracolumbar intervertebral disk extrusion. J Am Vet Med Assoc. 2012;241:754-9.

12. Valverde A, Dyson DH, McDonell WN. Use of epidural morphine in the dog for pain relief. Vet Comp Traumatol. 1989;2:55-8.

13. Leibetseder EN, Mosing M, Jones RS. A comparison of extradural and intravenous methadone on intraoperative isoflurane and postoperative analgesia requirements in dogs. Vet Anaesth Analg. 2006;33:128-36.

14. Bosmans T, Schauvliege S, Gasthuys F, Duchateau L, Marcilla MG, Gadeyne C, Polis I. Cardiovascular effects of epidural administration of methadone, ropivacaine $0.75 \%$ and their combination in isoflurane anaesthetized dogs. Vet Anaesth Analg. 2011;3:146-57.

15. Cousins MJ, Mather LE. Intrathecal and epidural administration of opioids. Anesthesiology. 1984;61:276-310.

16. Almeida TF, Fantoni DT, Mastrocinque S, Tatarunas AC, Imagawa VH. Epidural anesthesia with bupivacaine, bupivacaine and fentanyl, or bupivacaine and sufentanil during intravenous administration of propofol for ovariohysterectomy in dogs. J Am Vet Med Assoc. 2007;230:45-51.

17. Cassu RN, Stevanin H, Kanashiro C, Menezes LMB, Laposy CB. Epidural anesthesia with lidocaine alone and in combination with fentanyl for ovariohysterectomy in dogs. Arq Bras Med Vet Zootec. 2008;60:825-31.

18. Brock N. Acepromazine revisited. Can Vet J. 1994;35:458-9.

19. Ilkiw JE, Pascoe PJ, Haskins SC. Cardiopulmonary and respiratory effects of propofol administration to hypovolemic dogs. Am J Vet Res. 1992;53:2323-7.

20. Torda TA, Pybus D. A comparison of four opiates for epidural analgesia. Br J Anaesth. 1982;54:291-5. 
Diniz MS et al.

\section{Correspondence:}

Renata Navarro Cassu

Faculdade de Medicina Veterinária-UNOESTE

Departamento de Cirurgia e Anestesiologia Veterinária

19067-175 Presidente Prudente - SP Brazil

Tel.: (55 18)3229-2077

navarro@unoeste.br

renavarro@uol.com.br

Received: March 20, 2013

Review: May 21, 2013

Accepted: June 18, 2013

Conflict of interest: none

Financial source: none

${ }^{1}$ Research performed at Veterinary Hospital, Department of Veterinary Surgery and Anestesiology, Faculty of Veterinary Medicine, Oeste Paulista University (UNOESTE), Presidente Prudente-SP, Brazil. 